\section{No alargues la mano contra los niños. ¡Levántalos! El sacrificio de los hijos de Abraham a partir de Gn 22,1-19*}

\author{
Maricel Mena-López ${ }^{a}$ \\ Universidad Santo Tomás, Colombia \\ http://orcid.org/0000-0001-5958-0570
}

RECIBIDO: 30-05-18. APROBADO: 02-10-18

\begin{abstract}
Resumen: Tradicionalmente los personajes bíblicos tienden a ser vistos como modelos y no como espejos de la actuación humana; por eso es casi un pecado cuestionar sus prácticas, aun cuando estas atenten contra la vida de niños y mujeres. Las Escrituras hebreas son tanto la historia nacional de un pueblo como un relato completamente religioso que narra los encuentros de este pueblo con su Dios. Los aspectos de esta historia nacional no siempre se ajustan a los ideales de la religión, ni ciertas cuestiones que se dan por sentadas en un texto determinado cumplen con los estándares necesarios en el desarrollo de la revelación. El presente artículo ve la historia del sacrificio de Ismael e Isaac a partir de las intrigas familiares y no solo desde el patriarca Abraham y su hijo amado Isaac. Así mismo, sustenta la hipótesis de que Gn 22 es una lectura midrástica de tradiciones anteriores, en especial del sacrificio de Ismael de Gn 21.
\end{abstract}

Palabras clave: Libro del Génesis; patriarcas bíblicos; sacrificios de niños en la Biblia; ética bíblica; hijos de Abraham.
Do not Raise Your Hand Against Children. Hold Them Up! The Sacrifice of Abraham's Children in the Light of Gen 22:1-19

AвSTRACT: Traditionally, biblical characters tend to be seen as models, and not as mirrors of human behavior, so it is almost a sin to question their practices, even when they attempt against the lives of children and women. The Hebrew Scriptures are both the national history of a people and a completely religious account of the encounters of this people with their God. The aspects of this national history do not always conform to the ideals of religion, nor do certain issues that are taken for granted in a given text meet the necessary standards in the development of revelation. This article addresses the story of Ishmael's and Isaac's sacrifices from the perspective of the family's intrigues and not only that of the patriarch Abraham and his beloved son Isaac. Likewise, it supports the hypothesis that $\mathrm{Gn} 22$ is a midrastic lecture of ancient traditions, especially Ishmael's sacrifice in Gn 21.

KeY wORDs: Book of Genesis; Biblical patriarchs; Sacrifices of children in the Bible; Biblical ethics; Abraham's children.

\section{Cómo CITAR:}

Mena López, Maricel. "No alargues la mano contra los niños. ¡Levántalos! El sacrificio de los hijos de Abraham a partir de Gn 22, 1-19". Theologica Xaveriana 188 (2019): 1-26. https://doi.org/10.11144/ javeriana.tx69-188.amcnls

\title{
Reconocimiento
}

Este artículo es resultado de investigación del proyecto "Modelos eclesiológicos - para una Iglesia en salida”, del Grupo Gustavo Gutiérrez O. P., Teología Latinoamericana, de la Universidad Santo Tomás (código 19465020).

*Artículo de investigación

${ }^{a}$ Autor de correspondencia. Correo electrónico: maricelmena@usantotomas.edu.co 


\section{Introducción}

La vida de los patriarcas y las matriarcas bíblicas incluye intrigas, celos, traición, rivalidad, engaño, mentira. ¿Acaso es posible olvidar el episodio de la venta de José en Egipto, por sus hermanos (Gn 37,1-35)? ¿O la simulación de Abraham de que Sara era su hermana ante el faraón egipcio (Gn 12,10-13-20,2)? ¿O la rivalidad entre las matriarcas Sara y Agar (16,1-159), Lía y Raquel, y de sus criadas Zelfa y Bila (Gn 29, 1-24)? ¿O el robo de Jacob de la primogenitura de su hermano mayor (Gn 27,1-40)? ¿O el engaño en el episodio del sacrificio de Isaac (Gn 22,1-19)? Estas historias son parte de una cadena de sagas familiares que se convierte en la historia de toda una nación.

Las intrigas al interior de la familia patriarcal podrían iluminar nuestra realidad presente. De ahí que nos preguntemos por la situación actual de las niñas y niños en sus hogares. ¿¿Serán estos espacios seguros de acogida y cuidado de la vida? O, por el contrario, ¿continuamos asistiendo silenciosamente al sacrificio de nińos y nińas bajo el manto del silencio, la complicidad y la reivindicación de un modelo familiar que constitutivamente se encuentra en crisis?

Las estadísticas algo nos revelan sobre el preocupante panorama colombiano en cuanto a la violencia contra niños, niñas y adolescentes. Así lo demuestran cifras proporcionadas por el Instituto Nacional de Medicina Legal y Ciencias Forenses de 2016:

De 26.473 eventos de violencia ocurridos en el contexto familiar, sin incluir la violencia de pareja, el 38,08 \% de las víctimas fueron niños, niñas y adolescentes (NNA), 6,24 \% adultos mayores y 55,67 \% otros familiares (consanguíneos y civiles). En las mujeres recayó el mayor porcentaje de las acciones violentas $(59,13 \%)$. La violencia contra niños, niñas y adolescentes fue más frecuente en menores, de 10 a 14 años de edad (33,33\%); sin embargo, la tasa por cien mil habitantes identificó como grupo de mayor riesgo a los adolescentes entre 15 y 17 ańos de edad $(97,99 \%)$. Los padres y madres fueron los principales agresores. ${ }^{1}$

Las estadísticas referidas a los crímenes perpetuados específicamente contra niñas revelan lo siguiente:

El 75,11 \% de los exámenes forenses corresponde a la población de niñas entre los 0 y 14 años. Las cifras reflejan que las niñas entre los 10 y 14 años son las que presentan mayor riesgo de ser víctimas de algún tipo de delito sexual, con 7.648 casos, equivalentes al 40,52 \%. El 10,65\% de los casos corresponden a niñas de 4 años de edad o menos, representado en 2.011 casos, cifra que triplica el número de casos valorados en niños (597). ${ }^{2}$

\footnotetext{
${ }^{1}$ Montoya, “Comportamiento de la violencia intrafamiliar, Colombia, 2016”, 211.

${ }^{2}$ Ibíd., 216.
} 
Este panorama tan preocupante no es parte de la agenda de paz en Colombia, aunque sí lo sea el reclutamiento y las violaciones a los derechos de los niños durante la guerra, constituidos como crímenes de lesa humanidad. Pese a ello, creemos que el crecimiento desaforado de los crímenes sexuales y asesinatos de niños y niñas en diferentes escenarios, principalmente en el ámbito de la casa, también merece atención, si realmente queremos una paz plena, estable y duradera.

$\mathrm{Al}$ estudiar Gn 22,1-19, no podemos dejar de pensar en tan escalofriantes cifras. Este pasaje es considerado el texto fundante de la fe de Israel, en el que Yahveh condena los sacrificios humanos, y más concretamente, los sacrificios de infantes ofrecidos en holocausto ${ }^{3}$, por lo que se convierte en un texto etiológico ${ }^{4}$ de la ética bíblica fundamentada en el no matar.

A pesar de la existencia de este imperativo ético por la historiografía deuteronomista, el sacrificio de niños parece haber sido una práctica ejercida por cananeos e israelitas en honor a Yahveh. Una de las mayores aportaciones que Eissfeld $t^{5}$ hizo fue referirse a Moloch, no como a un dios cananeo, y sí como un término técnico para un sacrificio humano, pese a la insistencia, de algunos eruditos -como Day ${ }^{6}$-, de separar a Yahveh del sacrificio de niños y transferírselos a Moloch.

La polémica nos está confirmando la existencia de sacrificios de niños en el Antiguo Medio Oriente, aunque no necesariamente dedicados a una deidad en especial. Verdaderamente algunos textos -como Jr 32,35 y 19,5- favorecen la teoría de que se trata de un sacrificio a Moloch y a Baal, y otros -como Ez 20,25-26; y Miq 6,6-7- nos revelan una práctica de oblación a Yahveh. Por eso, en este texto vamos mucho más allá de un sacrificio de orden divino, aunque tal elemento no sea para nada irrelevante, ya que justamente por ello, en la actualidad, algunos grupos religiosos justifican abusos contra niños y niñas.

En Gn 22,1-19 tenemos el sacrificio de un niño supuestamente ordenado por Yahveh, y como parte del dramatismo en que se desarrolla esta escena, el autor insiste en que se trata del único hijo de Abraham, pero omite el sacrificio previo de su otro hijo, Ismael, en Gn 21, 8-21, aunque este último no fuera por causas religiosas sino morales. Tal omisión podría apuntar a que estamos ante dos unidades de tradiciones

\footnotetext{
${ }^{3}$ Posiblemente sacrificios ofrecidos al dios Moloch, evidenciados en excavaciones arqueológicas (Wood, "Jar-Burial Customs and the Question of Infant Sacrifice", 227-234).

${ }^{4}$ La finalidad de un relato etiológico - bien sea oral o escrito- es fundamentar el origen de una tradición, institución o fenómeno natural. En este caso sería el origen del no matar en la tradición bíblica.

${ }^{5}$ Eissfeld, Molk als Opferbegriff im Punischen und Hebräische und das Ende des Gottes Moloch.

${ }^{6}$ Day, "Molech: A God of Human Sacrifice in the Old Testament".
} 
diferentes: una que realza la descendencia de Ismael y la esclava egipcia, y otra que privilegia la de Isaac y su padre.

Génesis 22,1-19 centra toda la atención en el dolor del padre, al punto en que este relato es llamado comúnmente como el sacrificio o drama de Abraham7, según el cual este es visto como el prototipo del testigo fiel y el judío ideal ${ }^{8}$, al mismo tiempo que como el gran transgresor de las leyes humanas?.

Sin embargo, ¿por qué no pensar también en el sacrificio de las madres y de sus hijos o en el silencio cómplice de mujeres y hombres frente a la perpetuación de estas violencias en la dinámica patriarcal? Vale la pena resaltar aquí que, si bien muchos comentaristas titulen estos versículos como el sacrificio de Isaac ${ }^{10}$, la atención siempre se la lleva el patriarca y no el infante. De allí que nos preguntemos: ¿ Es posible entender esta saga a la luz de los conflictos ${ }^{11}$ familiares y de sus relaciones padre-madres-hijos y de estos con Dios? Y estos crímenes atroces contra los nińos de ayer y de hoy ¿cómo interpelan a la religión patriarcal y adultocéntrica de nuestras sociedades?

$\mathrm{Al}$ tener presentes estas preguntas iniciales, para el desarrollo del presente texto tomamos como base Gn 22,1-19, por considerarlo el punto álgido de toda la saga de Abraham. Esta es una de las historias que más ha despertado interés en el campo de la teología bíblica, así como curiosidad por parte de lingüistas, filólogos, filósofos ${ }^{12}$, historiadores y $\operatorname{artistas}^{13}$. Quizás dicho interés se deba a que estamos ante una de las sagas patriarcales más enigmáticas, desde los puntos de vista teológico y narrativo. Es considerada como una de las obras primas de la literatura eloísta ${ }^{14}$, y uno de los textos más pulidos y magistralmente armados entre los textos patriarcales.

Cuestionaréla práctica sacrificial de infantes como un tema real y controvertido al interior del corpus legal veterotestamentario ${ }^{15}$. Y asumiré la participación de varias tradiciones en la composición final de esta perícopa, consciente de que la hipótesis literaria del Pentateuco fue llevada al banquillo de los acusados, por lo que hoy ha

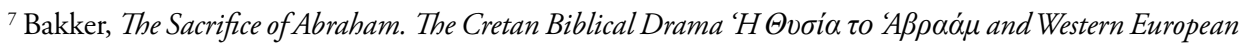
and Greek Tradition, 5.

${ }^{8}$ Gregory, "Abraham as the Jewish Ideal: Exegetical Traditions in Sirach 44:19-21", 66-81.

${ }^{9}$ Kierkegaard, Temor y temblor.

${ }^{10}$ Kessler, Bound by the Bible. Jews, Christians and the Sacrifice of Isaac.

${ }^{11}$ Gaiser, "Sarah, Hagar, Abraham - Hannah, Pehinnah, Elkanah: Case Studies in Conflict", 237-284.

${ }^{12}$ Derrida, Dar la muerte, 121.

${ }^{13}$ Hernández, "El sacrificio de Isaac", 65-78.

${ }^{14}$ Bergen, "The Role of Genesis 22:1-19 in the Abraham Cycle: A Computer-Assisted Textual Interpretation", 313-326.

${ }^{15}$ Dewrell, Child Sacrifice in Ancient Israel.
} 
caído en desuso, al mismo tiempo que comparto la hipótesis reciente de una escuela literaria deuteromísta (D) y otra sacerdotal (P) que intervino en la redacción final del texto. Además, intentaré mantener viva la memoria de las tradiciones femeninas, en este caso, de Sara y $\operatorname{Agar}^{16}$, a partir de las cuales se forman dos naciones importantes para el futuro de Israel.

Un análisis inicial al contexto de la saga de Abraham es fundamental para la ubicación textual de nuestra perícopa. En este recorrido también resulta pertinente presentar la estructura del texto de Gn 22,1-19 seguida de un análisis de la secuencia narrativa ${ }^{17} \mathrm{y}$ una aproximación socioteológica del relato ${ }^{18}$, para finalmente presentar algunas consideraciones conclusivas del estudio propuesto.

\section{El ciclo de Abraham y las intrigas contra Agar y su hijo}

Sin lugar a dudas, la aproximación estructural al ciclo de Abraham servirá para la identificación de los centros temáticos más relevantes de esta historia, y de esta manera para percibir las intencionalidades comunicativas de nuestra perícopa, ya que de entrada se nota un esfuerzo consciente en la redacción final del relato por establecer una relación entre todo el ciclo de Abraham con este pasaje.

La saga hace parte de la denominada época patriarcal (Gn 12-50). En estos capítulos se contemplan sagas familiares en torno de los patriarcas de Israel, y el estudio de cada uno de ellos se denomina ciclo ${ }^{19}$. Así podemos dividir este bloque en cuatro ciclos: (1) El ciclo de Abraham (Gn 12-23). (2) El ciclo de Isaac (Gn 24-27). (3) El ciclo de Jacob (Israel) (Gn 28-36). (4) El ciclo de José (Gn 37-50).

Presentamos a continuación la aproximación al ciclo de Abraham según la estructura proporcionada por Bergen.

\footnotetext{
${ }^{16}$ Momanyi, "The Children of Sarah, Hagar and Mary. A Feminist Perspective on Judaism, Islam and Chistianity", 73-87.

${ }^{17}$ La secuencia narrativa prestará atención al desencadenamiento de los acontecimientos en un texto narrativo. Por tanto, no se hará un análisis desde el punto de vista del narrador bíblico, pues a mi criterio este trabajo ya ha sido explorado por autores como Barrios, "Del sacrificio de 'Abrahan' al sacrificio de su 'descendencia': exégesis y teología narrativa del sacrificio en Génesis 22,1-19”, 15-55; y Camelo, "Padre... y ¿̇ónde está el cordero para el holocausto? Una aproximación literaria a la Aquedá en Génesis 22,1-19”, 99-126.

${ }_{18}$ Para el análisis socioteológico tendremos en cuenta la obra de Gottwald, La Biblia hebrea. Una introducción socio-literaria, 1992.

${ }^{19}$ Por ciclo se entiende una serie de relatos que giran en torno de un determinado personaje: este aparece como el protagonista de los acontecimientos narrados.
} 
Tabla 1. Aproximación al ciclo de abraham

\begin{tabular}{|c|c|c|}
\hline División & Texto & Contenido \\
\hline 1 & $11,27-32$ & Introducción \\
\hline 2 & $12,1-9$ & Llamada a salir de Canaán \\
\hline 3 & $12,10-20$ & Abraham en Egipto \\
\hline 4 & $13,1-8$ & Separación de Abraham y Lot \\
\hline 5 & $14,1-24$ & Abraham rescata a Lot \\
\hline 6 & $15,1-21$ & El Dios de la alianza con Abraham \\
\hline 7 & $16,1-16$ & El sacrificio de Agar e Ismael \\
\hline 8 & $17,1-27$ & Circuncisión \\
\hline 9 & $18,1-15$ & Aparición en Mambre \\
\hline 10 & $18,16-33$ & Intersección de Abraham por Sodoma \\
\hline 11 & $19,1-30$ & Sodoma y Gomorra son destruidas \\
\hline 12 & $19,31-38$ & Lot y sus hijas \\
\hline 13 & $20,1-18$ & Abraham y Ebimelec \\
\hline 14 & $21,1-7$ & Nacimiento de Isaac \\
\hline 15 & $21,8-21$ & El sacrificio de Agar e Ismael \\
\hline 16 & $21,22-34$ & Abraham y Ebimelec en Bersabeia \\
\hline 17 & $22,1-9$ & $\begin{array}{c}\text { Abraham es puesto a prueba } \\
\text { (sacrificio de Isaac) }\end{array}$ \\
\hline 18 & $22,20-24$ & Hijos de Nacor \\
\hline 19 & $23,1-20$ & Tumba de los patriarcas \\
\hline 20 & $24,1-66$ & Matrimonio de Isaac \\
\hline 21 & $25,1-11$ & Muerte de Abraham \\
\hline
\end{tabular}

Fuente: Bergen, Robert. "The Role of Genesis 22:1-19 in the Abraham Cycle: A ComputerAssisted Textual Interpretation" (Criswell Theological Review 4/2 [1990]), 316.

Según Bergen, la propuesta de división del ciclo de Abraham en 21 secciones apunta al hecho de que Gn 22,1-19 es el clímax de la narrativa, ya que allí el nombre de Abraham aparece 19 veces y este número es elevado en comparación con las otras secciones donde dicho nombre aparece ${ }^{20}$. Para este autor, el redactor usó el nombre del personaje principal en la parte crucial de la historia.

Otra razón para seleccionar Gn 22,1-19 como el centro temático es la localización de esta perícopa en la extensión global del texto. Para Bergen, la tendencia de los narradores en toda cultura es ubicar la sección narrativa que está siendo codificada

${ }^{20}$ Bergen, "The Role of Genesis 22:1-19 in the Abraham Cycle: A Computer-Assited Textual Interpretation, 315 . 
como más significativa en el 50 \% final del texto global, y la división 17 encaja -según él- en este criterio. Además, la sección repite verbos y asuntos tratados en otras partes del macrorrelato ${ }^{21}$. Finalmente, Bergen argumenta que una tendencia narrativa de los escritores veterotestamentarios consiste en ubicar el discurso más extenso en la parte principal de todo el macrorrelato, de manera que, de los 35 discursos pronunciados por Dios o por el ángel, en todo este ciclo, 19,15-18 es el más extenso ${ }^{22}$.

Aunque los argumentos de Bergen son convincentes y concordemos con él en que estamos ante un texto neurálgico para la comprensión del ciclo literario desde la óptica del redactor final, nos atrevemos en este estudio a establecer dos centros que -a nuestro modo de ver-son los más significativos del ciclo, a partir del mismo esquema proporcionado por este autor.

Si tomamos en cuenta la importancia del número 7 como plenitud, en la numerología bíblica, el primer centro temático observado sería Gn 16,1-16. En esta sección narrativa, Sara ofrece a Abraham, como mujer, a su esclava egipcia Agar, con quien tiene a su primer hijo, Ismael. En este pasaje llaman la atención los celos de Sara por causa de la maternidad de Agar (v. 3), quien según el texto la miraba con desprecio.

Como consecuencia de los malos tratos de Sara, Agar huye al desierto y allí ella experimenta su primera teofanía ${ }^{23}$ : el ángel le ordena regresar con su ama, no sin antes prometerle descendencia numerosa ${ }^{24}$, por lo que Ismael es también hijo de la promesa.

Otro elemento revelador de este pasaje consiste en que Agar no solo obedece, sino que se atreve a dar nombre a Yahveh al llamarlo el Roi (el que ve), y todo esto sucede entre Cades y Béred donde fue levantado un pozo llamado Lajai Roi (pozo del viviente que me ve).

El segundo centro se encuentra también en la sección 7 contada de abajo para arriba. En esta ocasión, la vida de Ismael nuevamente peligra (Gn 21,8-21): su descendencia se ve amenazada ante un nuevo destierro como consecuencia de un mandato de Sara. Durante su estancia en el desierto y ante la inminente muerte de su hijo, Agar experimenta una nueva teofanía.

Según la intuición de Eissfeldt, al caracterizar la raíz mlk como sacrificio humano, el abandono de un niño en el desierto podría ser otro tipo de sacrificio de infantes que no estaba directamente ligado a unas prácticas religiosas o a divinidad alguna.

${ }^{21}$ Ibíd., 317.

${ }^{22}$ Ibíd., 317.

${ }^{23}$ Usualmente los autores suelen distinguir entre la experiencia de manifestación de los hombres, teofanía, y la de las mujeres, epifanía.

${ }^{24}$ Nótese que, por lo general, esta promesa es dada a los varones, y que hay pocos textos en los que la divinidad se le revela a las mujeres y les promete descendencia. 
$\mathrm{Al}$ volver a poner la mirada sobre el relato de Agar, tenemos que el Señor escucha nuevamente su aflicción, envía al ángel y este la llama desde el cielo; después Dios abre los ojos de Agar y ella ve otra vez un pozo de agua del que -en esta ocasión- quien bebe es su hijo, favorecido con la continuidad de su prole.

Otro elemento que vale la pena observar de la estructura proporcionada por Bergen: entre un centro y el otro hay siete secciones. De esto podríamos concluir que los centros temáticos del ciclo de Abraham están fundamentados en narrativas femeninas en las cuales Sara y Agar son las protagonistas, su presencia es activa y Abraham es un actor secundario sometido al querer de Sara, reafirmado por Dios, pese a que ella no habla directamente con él.

Por su parte, Agar es también sometida por su ama y por el patriarca, quien cumple las órdenes de su esposa; y de manera parecida a Abraham, Agar habla directamente con Dios; más aún, ella se encuentra con él $(\mathrm{Gn} 16,13)$, recibe la promesa en el Capítulo 16 (que es ratificada en el 21) y recibe, a través de su descendencia, la bendición que era pronunciada solo al varón escogido por Dios.

\section{Criterio artístico-literario de la estructura de Gn 22,1-19}

Esta narrativa ha estado sujeta a varias propuestas estructurales. Towner ${ }^{25}$, por ejemplo, ofrece una estructura concéntrica, en la que los vv. 11-12 son justamente el centro en la escena donde el ángel del Señor detiene a Abraham, antes de consumar el sacrificio de su hijo, como recompensa de su fe.

Römer ${ }^{26}$ por su parte, divide el centro de la perícopa en dos partes: vv. 4-5, donde Abraham habla a los jóvenes, y vv. 6-8, donde Abraham habla con su hijo Isaac.

Brueggemann ${ }^{27}$ divide la sección en tres series, con el criterio de la convocación y la respuesta de Abraham, y establece el centro lo establece en el v. 8, específicamente en la expresión Dios proveerá cordero para el holocausto.

Coats ${ }^{28}$ estructura el texto teniendo en cuenta su desarrollo narrativo, y resalta tres elementos: la exposición, la complicación y la resolución, más una conclusión. Para este autor, el enfoque de la prueba nissäh recae en la obediencia, la integridad y la lealtad.

\footnotetext{
${ }^{25}$ Towner, Genesis, 185.

${ }^{26}$ Römer, "Abraham's Righteusness and Sacrifice: How to Understand (and Traslate) Genesis 15 and 22", 4.

${ }^{27}$ Brueggemann, Teología del Antiguo Testamento un juicio a Yahvé. Testimonio. Contención. Defensa, 581-588.

${ }^{28}$ Coats, “Abraham's Sacrifice of Faith: A Form-Critical Study of Genesis 22", 392.
} 
Lo común en las tres primeras estructuras es la búsqueda de un centro, en cuanto el análisis narrativo de Coats no tiene esa intencionalidad. Ciertamente el texto se ha prestado para numerosos análisis estructurales, y por esto sugerimos otra estructura que atiende más al criterio artístico y literario de la perícopa que a la búsqueda de una estructura concéntrica:

Prólogo: 22,1

Sección I: Orden/crisis 22,2-10

Escena 1: 22,2-5

Escena 2: 22,6-10

Sección II: Resolución 22,11-18

Escena 1: 22,11-14

Escena 2: 22,15-18

Epílogo: 22,19

La increíble historia de Abraham e Isaac comienza presumiblemente con la referencia de que Abraham permaneció en la tierra de los filisteos (Gn 21,3) y concluye con la noticia de su regreso a Beersheba con sus dos siervos. Es una narrativa muy bien dispuesta en dos secciones, con evidente talento artístico y literario. El episodio de Gn 22,1-19 se lee como una pieza en dos actos delimitada por su Prólogo y su Epílogo. La primera sección tiene dos escenas: 22,2-5 y 22,6-10; y la segunda sección tiene la misma secuencia de dos escenas: 22,11-14 y 22,15-18.

Llama la atención la utilización de una declaración de tipo repetitivo en el v. 11: ¡Abraham! ¡Abraham! Ella divide la historia en dos momentos. El uso de tu hijo, tu único hijo en tres ocasiones (vv. 2, 12 y 16) tiende a aumentar la gravedad de la situación. También se evidencia una gran tensión, como si Dios quisiese recordarle que la prueba es demasiado grande. La repetición de la expresión los dos caminaron juntos (vv. 6 y 8) también aumenta la tensión y eleva el clímax de la narrativa.

Se percibe además una cierta asimetría entre las dos partes, y en ambas se evidencia el uso de tensiones y resoluciones. Llaman la atención los imperativos toma, ve y ofrece (v. 2) y las negaciones no extiendas, no hagas, no negaste (v. 12). Además, se repite la fórmula de bendición de los vv. 17 y 18. La referencia al hijo único del inicio es contrastada con la expresión multiplicaré grandemente tu descendencia como las estrellas del cielo y la arena de la playa (v. 17). El texto fornece un elemento clave de transición en el v. 16: esto sucede por causa de que hiciste esta palabra y no negaste a tu hijo, tu único. 
El énfasis en la expresión "tu único" proviene de la teología deuteronomista, de la que legamos la idea de un Dios único, un solo pueblo, un solo santuario ${ }^{29}$, en especial el nombre Yahveh, que aparece tan solo en los vv. 11, 14, 15 y 16 como añadidos al relato eloísta inicial.

Según los datos proporcionados por Westermann ${ }^{30}$, los vv. 15-18 no hacen parte de la obra original adjudicada a los escritores eloístas; para ellos, ello es obra de un redactor secundario jeovista. De acuerdo con este aporte, la memoria oral o escrita inicialmente eloísta fue releída a la luz de la teología yahvista deuteronomista, para sintetizar magistralmente la teología yahvista del Pentateuco, cuya redacción final recibió influencia de la teología sacerdotal de finales del Imperio babilónico e inicios del Imperio persa, época en la que se erradica definitivamente la idea de que Yahveh permitía los sacrificios humanos.

Otro argumento en favor de una redacción tardía lo encontramos en el uso del nombre de Dios con artículo ha elohim (el Dios), expresión característica de finales del periodo persa e inicios del periodo helenístico, para denotar un Dios distante e incomprensible. Este Dios es utilizado únicamente por el narrador y no por Abraham. Así pues, la deidad que desea que Abraham realice el sacrificio de su hijo es ha-elohim y la que lo salva es Yahveh; es como una especie de transición y triunfo definitivo del yahvismo sobre las demás deidades; más aún, se percibe claramente la intencionalidad de la redacción final: enfatizar en la obediencia y la recompensa, típica de los deuteronomistas.

La experiencia inicialmente descrita como la prueba es transformada finalmente en bendición. El punto crítico de la historia, el v. 10, en el que Abraham extendió la mano y cogió el cuchillo para inmolar a su hijo, divide las dos partes. La primera mitad (vv. 1-9) enfatiza en la prueba. El sacrificio del niño se desvanece en la segunda parte, cuando es presentado el sacrificio de animales, y se da a entender que se trata de un relato etiológico cuya finalidad es justificar, por un lado, la distancia entre el Dios de los israelitas y los sacrificios de niños que la religión cananea practicaba en honor al dios Moloch, y por otro, explicar el origen de los sacrificios expiatorios de animales, tan comunes en los ritos de Yahveh. El empleo de esta técnica, además de despertar el interés por la narrativa, ayuda en la comprensión del contenido del texto.

Este es el relato más explícito de un sacrificio de niños en la Biblia. Otras referencias -como los sacrificios de la hija de Jefté (Jc 11,29-40) o del primogénito del

\footnotetext{
${ }^{29}$ Weippert, "Das deuteronomistische Geschichtswerk. Sein Ziel und Ende in der neueren Forschung", 213-249.

${ }^{30}$ Westermann, Genesis 12-36, 237.
} 
rey de Moab (2Re 3,27)- son menos detallados, pero podemos encontrar rastros de sacrificios de nińos que aun cuando no hicieran parte de rituales, muchas veces eran realizados por sus propios padres; en otros casos, los menores eran asesinados en razón de la ira de Yahveh y/o en su nombre (2S 21,6; Ez 20,25-26).

Algunos códigos de la Ley bíblica exigen que el primogénito del ganado y las manadas se entreguen en sacrificio a Yahveh (Ex 13,12-16; y 34,19), mientras otros pasajes sugieren que el requisito también se aplica a los primogénitos (2Re 3,27; Ez 20,26). En la mayoría de casos, los primogénitos deben ser "redimidos" mediante la ofrenda de una oveja (Ex 34,19-20) o un pago en efectivo a los sacerdotes ( $\mathrm{Nm}$ 18,15-16). Sin embargo, en al menos un caso no se menciona ninguna forma de redención (Éx 22,28-29), lo que posiblemente indica que los primogénitos fueron sacrificados en algunos círculos yahvistas ${ }^{31}$.

\section{Análisis estructural: entre pruebas, engaños, silencios y ocultamientos}

En este apartado seguiremos la secuencia narrativa del relato, según la estructura propuesta.

\section{El Prólogo. Elohim probó a Abraham $(22,1)$}

El Prólogo $(22,1)$ introduce el relato: aquí Dios se dirige a Abraham para probarlo. El mandato viene directamente de Dios, es él quien lo llama y lo prueba ¿Qué intenciones tiene Dios? ¿Hacer pasar un mal rato a su amigo? Probar, ¿con relación a qué y para qué? Al parecer, esta prueba es un tipo de pacto secreto entre Dios y Abraham, como lo sugiere Kierkegaard ${ }^{32}$; y de la manera como esta prueba se ejecute dependerá el desenlace de la narrativa. En el v. 12 se da la razón: Dios quería ver si Abraham le temía ${ }^{33}$. Todo esto sucede después del pacto con Abimelek, en Bershebá.

La respuesta de Abraham frente al llamado de Dios (v. 1) pone al lector en sintonía con la perícopa anterior, pese a que autores como Von $\operatorname{Rad}^{34}$ sostienen que existe solo una vaga relación entre Gn 22,1-19 y 21,22-33. Para Coats, por el contrario, "el esquema del itinerario patriarcal está en el contexto de esta historia" ${ }^{35}$. La

\footnotetext{
${ }^{31}$ Dewrell, Child Sacrifice in Ancient Israel.

${ }^{32}$ Kierkegaard, Temor y temblor.

${ }^{33}$ Sobre el temor de Dios-YHWH la Biblia abunda en textos (ver Gn 20,11; 2S 23,3; Is 11,2-3; el libro de los Proverbios, etc.); el verbo yare’ significa temer, venerar, respetar, admirar.

${ }^{34}$ Von Rad, Genesis, 293.

${ }^{35}$ Coats, “Abraham's Sacrifice of Faith: A Form-Critical Study of Genesis 22”, 392.
} 
unidad con el contexto anterior se sostiene tanto por el itinerario patriarcal como por la importancia de esta narrativa en una perspectiva teológica relacionada con el lugar donde suceden los acontecimientos. Es así como Abraham parte de Bershebá a la montańa, para el sacrificio, y regresa nuevamente allí (v. 19).

\section{Primera sección. Orden y crisis $(22,2-10)$}

La primera sección intitulada "Orden y crisis" $(22,2-10)$ se divide en dos escenas bien delimitadas.

\section{Primera escena. Toma a tu único hijo (vv. 2-5)}

Esta escena transmite las instrucciones básicas dadas a Abraham, junto con su respuesta inicial. Llama la atención el uso de tres imperativos toma, ve, ofrece (v. 2). Según Römer ${ }^{36}$, estas raíces son típicas de contextos de peregrinaciones, y por tanto, el texto presentaría a Abraham como prototipo de un peregrino. De todas formas, es una orden contundente.

Sin embargo, ¿quería realmente Abraham sacrificar a su hijo? ¿Cuál es la naturaleza del Dios de Abraham? Él instruye a Abraham a tomar determinadas acciones que pueden resultar en la ruptura de sus lazos familiares. También sorprende la calma de Abraham y su acción inmediata. Él madruga, tomó su burro, lleva consigo a dos jóvenes y la madera; y al llegar a la tierra de Moriá y divisar la montaña para el sacrificio, Abraham ordena a los siervos quedarse allí.

La referencia geográfica a las montañas haim de Moriá conduce a algunos autores a especular sobre el origen de este relato, para ubicarlo inclusive en el tiempo del rey Salomón, al aludir al dato que aparece en 2Cro 3,1 donde Moriá sería el lugar de edificación del Templo de Jerusalén. No obstante, consideramos que dicho dato es insuficiente en términos de una ubicación tan temprana del relato, por lo que la referencia a las montañas sería más de carácter teológico que histórico. Esto toma fundamento si recordamos que los acontecimientos claves de revelación de Yahveh suceden en una montaña como la del Sinaí o el monte Carmelo.

\section{Segunda escena. Tomó la leña para el holocausto (vv. 6-10)}

En este punto, la narrativa eleva su nivel de tensión, y el escritor emplea los tres verbos que la caracterizan: tomar la leña, poner sobre Isaac, tomar el fuego y el cuchillo (v. 6). El lector se queda en suspenso por el interludio caminan juntos.

\footnotetext{
${ }^{36}$ Römer, “Abraham's Righteusness and Sacrifice: How to Understand (and Traslate) Genesis 15 and 22", 4.
} 
El único diálogo registrado entre el padre y el hijo se encuentra en los vv. 7 y 8 . Vale la pena notar que la mentira es uno de los recursos utilizados por el patriarca en momentos de crisis (ver Gn 12,10-20 y 20,1-18). En este caso, se puede decir también que Abraham engaña a su hijo al no decirle lo que está pasando; al parecer la intencionalidad del redactor es justificar la mentira hasta el punto de que el lector infiere que la verdad es algo que en ese momento no puede ser dicha.

Este hecho nos permite preguntarnos si el engaño era el único mecanismo viable. También resulta cuestionable la actitud obediente de Isaac, en cuanto que la sumisión al padre denota también una ciega fe y obediencia a Dios; pero podría entenderse también que Isaac es un objeto pasivo en el relato, cuya única importancia es ser víctima del cumplimiento de un mandato.

En el v. 8, Abraham afirma que Dios proveerá el cordero para el holocausto. ¿Sabía Abraham que no sucedería nada malo con su hijo? ¿Explicaría esto el hecho de que el relato no presenta la reacción psicológica de los personajes, ya que ni el padre ni el hijo se conmueven cuando llega el momento del sacrificio? En el relato priman las acciones, no los sentimientos, ni la dignidad del infante, quien es conducido como oveja al matadero; sus posibles susurros, lloros, gritos y cuestionamientos simplemente no cuentan.

Por su parte, en el v. 9, se describe el lugar y el modo como el sacrificio fue preparado (construyó el altar, dispuso la leña, ató a su hijo y lo puso sobre el altar). Este sacrificio se yuxtapone al sacrificio del cordero que será inmolado más adelante. Sin embargo, ¿cuál es el papel de Isaac? Él aparece enmudecido, atado y sometido a la obediencia hasta ser puesto sobre la leña, como si no supiera lo que iba a suceder.

El v. 10 es la continuidad del versículo anterior, lo cual se percibe por el uso de la conjunción "y". Una nueva triada aparece: extender, tomar, degollar y estamos en el punto álgido de la descripción de la crisis, crisis que no existe, ya que extender la mano parece una actitud de ocultamiento, como si el cuchillo estuviese escondido a los ojos del muchacho. Ello se puede entender como el mantenimiento de la mentira con la que se inició el episodio, o su ingenuidad, al no percatarse de lo que está pasando.

\section{Segunda sección. Resolución (22,11-18)}

\section{Primera escena. Y llamó el ángel de Yahveh a Abraham (vv. 11-14)}

En esta escena, el ángel de Yahveh interviene para impedir que se le haga daño al muchacho. Este es un momento nuevo en el que, para salvar la vida del joven, Dios llama a Abraham, y este responde siempre de la misma forma: una respuesta preparada, estereotipada, en un marco único (“Heme aquî", en los vv. 1 y 11). 
Para el lector, estos versículos son un alivio, más incluso cuando aparece de la nada el cordero para el holocausto. Así se cumple la respuesta que Abraham le había dado a su hijo: Yahveh proveerá. Para completar, también sorprende el comentario del ángel: Yo sé que temes a Elohim (v. 12). Este comentario confirma que lo que se le había pedido a Abraham era una prueba.

Una vez más es sorprendente la pasividad de Isaac, quien a pesar de ser tenido como el heredero de la promesa, no actúa, sino está a merced del actuar de su padre. En esta dinámica patriarcal, los hijos no tienen ninguna importancia en las decisiones familiares, incluso cuando estas tienen que ver con su futuro y su propia vida.

\section{Segunda escena. Y llamó el ángel de Yahveh a Abraham (vv. 15-18)}

La bendición promulgada aquí está estrechamente relacionada con la actitud y disposición de Abraham de ofrecer a su hijo. Esto se evidencia con claridad en las expresiones por cuanto has hecho esto y no me has rehusado a tu hijo. El anuncio de la bendición también es expresado por la triada bendecir, multiplicar y heredar, característica del redactor.

La fórmula de bendición que aparece en la narrativa no es del todo nueva para el ciclo de Abraham (ver Gn 12, 15, 17). Otro elemento que llama la atención reside en que la bendición es sobre la descendencia numerosa, pero también incluye un lenguaje militar de sumisión de otros pueblos (v. 18), de modo que Dios somete a Abraham y, así mismo, este someterá a las naciones, y además heredará de ellas.

\section{Epílogo: Y vio Abraham a sus siervos 22,19}

Es de especial interés el aviso de que Abraham regresó al encuentro de los jóvenes y juntos regresaron a Beersheba; y es extraña la ausencia de mención de Isaac en este versículo. No hay indicación alguna de que él regresa con su padre, ni indicios de que permanece en Moriá. El texto omite esto, de manera que la atención del lector se concentra en Abraham, en su prueba de obediencia, y no en el infante Isaac.

\section{Consideraciones gramaticales generales}

Al leer Gn 22,1-19 nos preguntamos: ¿Cuál es la función del relato? ¿Solo resaltar la obediencia de Abraham? ¿A qué se debe la ausencia de sentimientos? El relato es trágico, pero carece de la reacción previsible de Abraham, mientras que su hijo es un instrumento pasivo.

También nos llama la atención el dramatismo en los diálogos. Dios prueba a Abraham mediante tres conversaciones: una entre Dios y Abraham, y dos entre el ángel 
y Abraham. Así mismo es importante mencionar que solo en una ocasión Isaac interpela a su padre sobre el cordero para el sacrificio (vv. 7-8), mientras que se queda callado cuando es atado y puesto sobre el altar o cuando el cuchillo se acerca a él (vv. 9-10).

Estas ocurrencias sugieren que el autor, además de poner a participar íntimamente al público en el episodio, organiza su texto de manera tripartita. El empleo discursivo sociolingüístico es altamente significativo y el uso del juramento es otro indicio de la importancia que el autor quiere dar al relato, no solo dentro del ciclo de Abraham sino también en toda la Torah, ya que Dios solo jura por sí mismo tres veces en el Pentateuco (Ex 13,11, 32,13, y 33,1).

Una de las maneras de concentrar la atención del público en una determinada sección del texto es a través de confrontaciones que presentan valores, ideas o conceptos contradictorios: por ejemplo, cuando Abraham tiene que escoger entre la preservación de su vida o la pérdida de su esposa (Gn 20,2). En este texto él debe escoger entre la obediencia a Yahveh o la vida de su hijo, a quien él ama. El mismo Dios que prometió que su hijo Isaac sería el heredero de la promesa (Gn 17,16; y Gn 19,21) ahora exige la muerte del joven a manos de su padre $(22,2)$. Esta es una gran paradoja. En los vv. 15-18 la teofanía con el ángel del Señor hace que el personaje principal del texto sea preeminente. Por otro lado, el empleo temporal de tres días (v. 4) es el periodo de preparación para los eventos más importantes, tanto del Antiguo como del Nuevo Testamento.

Al tomar en cuenta los elementos precedentes, bien podríamos decir que se trata de un relato reelaborado con finalidad teológica. Además de resaltar la obediencia de Abraham, en cuanto temeroso de Dios, el relato habría servido para decir algunas cosas más. Por ejemplo, justificar:

1. El rechazo de los sacrificios humanos que eran realizados en los santuarios cananeos:

- $\quad$ el rescate, y no sacrificio de los primogénitos varones;

- el culto como expresión de la voluntad divina;

- $\quad$ el significado religioso de un determinado lugar (ver v. 14).

2. La renovación de la promesa de bendición de Dios en favor de Abraham y su descendencia (ver 15,5.18; 16,10).

3. El no matar como ética fundante de la fe abrahámica.

Para concluir, vale la pena señalar que el sacrificio de niños es de los crímenes más abominables, por lo que la ética veterotestamentaria fundamentada en Yahveh quiere establecer una diferencia con relación a los llamados cultos paganos. El "humanismo deuteronomista" (Dt 12,31 y 18,10; 2Re 3,27, 16,3, 17,17, y 21,6) ha contribuido 
a desligar estas prácticas perversas del monoteísmo israelita, sin conseguir trascender este ideal en la historia. Por ello resulta desesperanzador el hecho de que, pasados casi tres milenios, continuemos en la lucha por garantizar el respeto pleno de derechos de los niños y niñas, así como su protección.

\section{Tradiciones femeninas en las teologías del pentateuco}

En cuanto a la dependencia literaria y a las tradiciones que están tras los relatos de sacrificio de Ismael e Isaac acudimos a las preguntas de Gaitan: “¿Hay formulaciones similares en textos literariamente independientes? ¿Hay una estructura común en la formulación? ¿Hay contenidos comunes? Y esos contenidos, ¿̇trasmiten un mismo mensaje?" ${ }^{37}$

Las respuestas a tales interrogantes tienen eco en la práctica de tradición midrástica en el Antiguo Israel. Este pueblo jamás consideró su historia como un hecho acabado. Consideraba que dicha historia debía reactualizarse para las necesidades de los tiempos. Esa práctica cobró mayor auge en la época del exilio babilónico, cuando los cautivos meditaban sobre la historia anterior y sobre la catástrofe nacional que les tocó sufrir ${ }^{38}$; y en tales meditaciones, el punto de partida era siempre la revelación anterior consignada en la Biblia, con la finalidad de sacar una enseñanza religiosa edificante para los miembros del pueblo de Israel. Este procedimiento, en el campo de la historia de Israel, se conoce como midrásh haggádico.

Para reforzar nuestra hipótesis en favor de una dependencia literaria y de una relectura midrástica entre el sacrificio de Isaac y el de Ismael, en el siguiente cuadro veremos con mayor exactitud los contrastes y similitudes ${ }^{39}$ entre ambas narrativas:

Tabla 2. Contrastes

\begin{tabular}{|l|l|}
\hline \multicolumn{1}{|c|}{ ISMAEL EN PELIGRo (GN 21) } & \multicolumn{1}{c|}{ IsAAC EN PELIGRO (GN 22) } \\
\hline $\begin{array}{l}\text { Crisis generada como resultado de una directiva } \\
\text { humana: Sara le ordena a Abraham que expulse a } \\
\text { Agar e Ismael (v. 10). }\end{array}$ & $\begin{array}{l}\text { Crisis generada por un resultado de una directiva } \\
\text { divina: Dios le dice a Abraham que ofrezca a Isaac } \\
\text { como sacrificio (v. 2). }\end{array}$ \\
\hline $\begin{array}{l}\text { Abraham en principio no quiere acatar la orden } \\
\text { (v. 11). }\end{array}$ & Abraham acata la orden (v. 3). \\
\hline $\begin{array}{l}\text { Sara es consciente de las circunstancias, ella generó } \\
\text { las circunstancias (vv. 9-10). }\end{array}$ & $\begin{array}{l}\text { Sara aparentemente no es consciente de las cir- } \\
\text { cunstancias. }\end{array}$ \\
\hline
\end{tabular}

${ }^{37}$ Gaitán, “Métodos de interpretación de la Biblia”, 158.

${ }^{38}$ Shwantes, Sufrimiento y esperanza en el exilio. Historia y teología del pueblo de Dios en el siglo VI a.C.

${ }^{39}$ Römer, "Abraham's Righteusness and Sacrifice: How to Understand (and Traslate) Genesis 15 and 22”, 7. 


\begin{tabular}{|l|l|}
\hline $\begin{array}{l}\text { Agar la madre de Ismael no podía quedarse para } \\
\text { ver morir a su hijo (vv. 15-16). }\end{array}$ & $\begin{array}{l}\text { Abraham, el padre de Isaac, no podía dejar de ver } \\
\text { (en verdad participando de) la muerte de su hijo. }\end{array}$ \\
\hline $\begin{array}{l}\text { La acción tiene lugar en el desierto de Beersheba } \\
\text { (v. 14). }\end{array}$ & La acción tiene lugar en la tierra de Moriá (vv. 2-4). \\
\hline
\end{tabular}

Fuente: Elaboración de la autora.

TABla 3. Comparaciones

\begin{tabular}{|l|l|}
\hline El primogénito expulsado se torna una nación. & Primogénito expulsado se torna una gran nación. \\
\hline $\begin{array}{l}\text { Dios prometió hacer una nación de Ismael, porque } \\
\text { él era la semilla de Abraham (v. 13). }\end{array}$ & $\begin{array}{l}\text { Dios prometió hacer una gran nación de Isaac, } \\
\text { porque Abraham no se rehusó. }\end{array}$ \\
\hline Abraham se levantó temprano en la mañana (v. 14). & Abraham se levantó temprano en la mańana (v. 3). \\
\hline $\begin{array}{l}\text { La intervención divina ocurre: El ángel de Elohim } \\
\text { llamó a Agar, se revierte el peligro (v. 17). }\end{array}$ & $\begin{array}{l}\text { Intervención divina ocurre: el ángel del Elohim } \\
\text { llama a Abraham; se revierte el peligro (vv. 11ss.). }\end{array}$ \\
\hline $\begin{array}{l}\text { Agua (vida-preservada) fue providencialmente } \\
\text { ofrecida (v. 19). }\end{array}$ & $\begin{array}{l}\text { Cordero (vida-preservada) fue providencialmente } \\
\text { ofrecido (v. 13). }\end{array}$ \\
\hline Agar vio entonces lo invisible (v..19). & Abraham vio un carnero invisible (v. 13). \\
\hline Agar se apropia del agua (v. 19). & Abraham se apropia del carnero (v. 13). \\
\hline $\begin{array}{l}\text { Agar, una egipcia, toma una esposa egipcia para } \\
\text { Ismael (v. 21). }\end{array}$ & $\begin{array}{l}\text { Abraham, un mesopotámico, tomó a una esposa } \\
\text { mesopotámica para Isaac (24,4). }\end{array}$ \\
\hline
\end{tabular}

Fuente: Elaboración de la autora.

La primera hipótesis que lanzamos acerca de dichas similitudes y contrastes consiste en que las narrativas patriarcales hicieron una relectura de las narrativas femeninas preexistentes y sobre tal base fundamentaron su teología ${ }^{40}$. En este sentido también vale la pena señalar que Gn 22,1-19 parece ser una relectura de las tradiciones egipcias, en las que las mujeres tienen relación directa con la divinidad. El autor sagrado no puede eliminar las memorias narrativas de mujeres egipcias ${ }^{41}$ para imponer sus narrativas y sustentar su ritualidad-religión.

Todo parte de peleas e intrigas en el seno de la familia de Abraham ${ }^{42}$. Las relaciones interpersonales están en desequilibrio: Sara siente que el futuro de su hijo está en peligro y la excusa perfecta reside en que un niño se ríe del otro. ¿Estará Ismael burlándose de su hermano, o simplemente se trata de un juego entre nińos? La palabra metzahek puede bien entenderse como risa y juego. El hecho es que Sara le exige a

${ }^{40}$ Las fuentes bíblicas dan cuenta que el nombre de Dios, Yahveh, fue usado antes que Moisés por madianitas, quenitas y probablemente egipcios, entre los que las mujeres cumplían funciones sacerdotales, y que luego de Moisés fue asumido como el Dios de los patriarcas (Mena-López, "Because of an Ethiopian Woman. Reflections on Race, Gender, and Religion”, 145-165).

${ }^{41}$ Desroches Noblecourt, La mujer en tiempos de los faraones.

${ }^{42}$ Pikaza, Mujeres de la Biblia judia, 40. 
Abraham que se deshaga de su otra mujer, y así la llama de forma despectiva: deshazte de aquella mujer y su hijo $(21,9)$.

La convivencia en la casa patriarcal está en crisis y Sara está dispuesta a tener una confrontación con su esposo, con tal de asegurar el futuro de su hijo y, sobre todo, de no criar su hijo junto a un esclavo. De hecho, Egipto siempre representó peligro y amenaza para los israelitas ${ }^{43}$, a pesar de haber sido su refugio durante largos años ${ }^{44}$. No obstante, los descendientes de Egipto también fueron herederos de la promesa, pues Esaú fue librado de la muerte, y para él hubo también una numerosa descendencia. Una de las posibles razones para justificar la actitud de Abraham es propuesta por Neoh al observar que la Ley y el amor son dos caminos posibles para entender la relación entre Abraham y su clan ${ }^{45}$.

Mientras que en Gn 21 se evidencia un fuerte liderazgo femenino, ya que todo se origina por una mujer y a una mujer el ángel se dirige, en Gn 21, ellas son las grandes ausentes. Con todo, pareciese que Dios quisiera dar una lección a Abraham y a Sara, al hacer exactamente lo mismo que ellos hicieron en contra del hijo de la esclava, pero esta vez es contra el hijo, el único, el bien querido, bien amado y no rechazado, Isaac. El texto es como una sátira a las acciones humanas.

En el primer relato, Ismael es cargado por su madre; ella es su protectora, pero parece no tener fuerzas o estar sometida de alguna manera, al dejarlo en un lugar retirado para no verlo morir, y permanecer en silencio. En el segundo relato, Isaac es silenciado, su voz no se deja escuchar en absoluto, no cuestiona a su padre más que para preguntarle por el animal del sacrificio.

Estas semejanzas y diferencias encontradas en los dos relatos nos hacen pensar que existen diversas tradiciones y redactores; por un lado se presta especial atención a las tradiciones femeninas, y por otro, se les resta protagonismo. Gn 21 es una especie de microrrelato que sirve de pretexto para la creación del macrorrelato de una gran nación.

Otros argumentos en favor de la idea de que Gn 22,1-19 está inspirado en narrativas anteriores son los siguientes:

1. Esta no es la única prueba por la que pasa Abraham: él es probado en la orden de salir de su tierra, dejando a su familia $(12,1)$, en la espera de su heredero (15,4-6); en el llamado a expulsar a su hijo Ismael; en el llamado a emprender una jornada con su hijo Isaac; pero a diferencia del Capitulo 12, estos dos llamados conllevarían la muerte del hijo de la esclava y la del hijo amado de Sara.

${ }^{43}$ Zucker, "What Sarah Saw: Envisioning Genesis 21:9-10", 54-62.

${ }^{44} \mathrm{~A}$ lo largo de la historia de Israel, Egipto fue considerado un lugar de refugio, antes de su formación como nación, durante el exilio y posexilio hasta la época del Nuevo Testamento.

${ }^{45}$ Neoh, "Law and Love in Abraham's Binding of Isaac", 237-261. 
2. Los herederos nacen de dos situaciones distintas ${ }^{46}$ : el primero, de una mujer fértil que posiblemente no es amada por el patriarca; y el segundo, de una situación difícil, pues su madre es estéril, pero antes de esto, Yahveh pone en peligro el destino de las mujeres Agar, en el desierto, y Sara, al ofrecerla a otro hombre (20,2-13); y los dos niños son puestos en peligro. Ambos serán herederos de grandes naciones $(21,12)$

3. La devoción de Abraham a Dios es evidente: le construye un altar para el sacrificio $(12,8 ; 13,18 ; 22,9)$; en dos ocasiones Abraham invoca el nombre de Yahveh, pero aquí hay una ofrenda real. Agar, aunque no le construye un altar, habla en dos ocasiones cara a cara con Yahveh. Son quizás las teofanías más amplias en todo el ciclo de Abraham.

4. La vida de Abraham es una historia de disidencias familiares: es separado de sus raíces ancestrales, su esposa es raptada en dos ocasiones (12,15; 20,3); dos veces Agar es puesta en peligro $(16,6 ; 21,14)$; se rompen los lazos con su sobrino $\operatorname{Lot}^{47}(13,11)$; y es separado de su primogénito Ismael.

5. Los vv. 15-16 constituyen el culmen de la fe revelada en la Torah: la fe obediente y sacrificial, la bendición de Abraham, la toma de la tierra. La bendición aparece siete veces, las declaraciones de bendición 12,2-4 son cumplidas pues mediante Abraham todas las naciones de la Tierra son bendecidas y las promesas del inicio son cumplidas. Esta es una clara característica de la teología deuteronomista: el binomio bendición-promesa.

6. Por primera vez el tema de la tenencia de la tierra aparece en 12,7 y es repetido en cuatro ocasiones en el ciclo de Abraham (13,14-17; 15,7-12; 17,8; 22,17); aunque tuvieran que librar batallas, Yahveh ya tendría resuelto el problema de la tierra.

Esta aproximación nos permitió tener una visión más amplia del ciclo de Abraham, al percibir cómo la narrativa se construye a partir de microrrelatos que son absorbidos e invisibilizados por el macrorrelato, el cual privilegia una historia contada desde los hombres en su relación con Dios, e invisibiliza las relaciones que se tejen entre Dios y los actores secundarios del metarrelato.

La mayoría de los estudiosos de los siglos XIX y XX ven Gn 22,1-19 como una explicación de la ausencia del sacrificio humano en la religión israelita, una leyenda etiológica, un cuento edificante de la obediencia; como símbolo de la fe veterotestamentaria

\footnotetext{
${ }^{46}$ Navarro Puerto y Fischer (eds.), La Torah, 263-304.

${ }^{47}$ Sobre Lot y sus hijas, ver a Navarro Puerto, Religión, sexualidad y violencia: lectura bíblica feminista de textos del Génesis, 69.
} 
en un Dios que exige una ciega obediencia. Este estudio quiso dar un paso adelante, al entender el relato analizado no solo como el clímax de cada una de las etapas de la relación entre Abraham y Yahveh, sino como un midrásh ${ }^{48}$ inspirado en otros episodios y, de manera más concreta, en la historia de Agar e Ismael.

Los argumentos en favor de una posible relectura inspirada en las relaciones previas entre la esclava Agar y su hijo Ismael, con el padre de este, se encuentran fundamentalmente en la ubicación de los dos relatos, como arriba explicamos, con base en el número 7 como expresión de totalidad. Es así como nos atrevemos a afirmar la importancia de Agar e Ismael en esta saga patriarcal, pues no son solo objetos pasivos sino juegan un papel en el mismo, ya que conocen a Yahveh y son sujetos de su atención, y por tanto, de su promesa.

\section{Aproximación socioteológica a la familia patriarcal}

El abrahámico es uno de los grupos que -en el transcurso del segundo milenioresistieron al sistema tributario cananeo ${ }^{49}$. Fue el que mejor describió la vida del seminómada porque su escenario natural fue la estepa. No obstante, se encuentran diferencias en los lugares que sus miembros frecuentaron: por ejemplo: Jacob habitó en Canaán central, Abraham e Isaac se desarrollaron en el sur, y vivieron en Sucot, Berseba, Belén, y Edom, entre otras localidades, todas ellas ubicadas en el sur estepario que rodea la zona fértil.

El grupo abrahámico adhirió al tribalismo entre los siglos XIII y XI a. C., en las montañas de Canaán. Sus integrantes percibieron las semejanzas entre su propio proyecto de vida y el de los grupos campesinos cananeos emigrantes de las planicies, entre otras, el que tanto los de las planicies como los de las estepas vivían en antagonismo con las ciudades-Estado (antagonismo que explica la alianza entre los grupos pastoriles y los grupos campesinos).

El contexto social del grupo abrahámico no era la ciudad. Más bien se encontraba alrededor de ella, y la veía negativamente (igual que los pastores y campesinos): en ella, las mujeres corrían peligro; y en ella ocurrían guerras y crímenes, o incluso se secuestraban niños para la guerra ${ }^{50}$. Sin embargo, los integrantes del grupo abrahámico no eran campesinos, pues no estaban presentes en los lugares típicos de la agricultura.

\footnotetext{
${ }^{48}$ Posiblemente se trata de un Midrásh hagádico, es decir, de una paráfrasis edificante, enriquecida con datos nuevos, a menudo legendarios, incluso fantásticos.

${ }^{49}$ Schwantes, Historia de los origenes de Israel, 61.

${ }^{50}$ Peterson, "Military Service as Child Sacrifice: Oedipal and Odyssean Perspectives", 36-52.
} 
Fueron criadores de ganado menor, ya que sus terrenos no daban para más. Fueron nómadas o seminómadas. Vivían en tiendas, dice Gn 18,1ss. Hombre y mujer tenían tiendas propias, lo que significaba cierta independencia económica. La expresión partir equivale a arrancar las estacas de la tienda. Emigraban de acuerdo con el clima y la lluvia (lo que se llama transhumancia); también en caso de hambre o de catástrofe política (lo que se llama transmigración: la historia de José y Jacob en Egipto muestra este tipo de migración).

La organización básica era el clan (grupo de familias en torno de un patriarca o matriarca que integraban una unidad social). Económicamente eran autosuficientes. No pagaban impuestos. Jurídicamente eran autónomos. Religiosamente no dependían de santuarios de ninguna ciudad-estado.

La tierra era vista como propiedad colectiva del clan. Los hombres cuidaban de los rebaños y las mujeres asumían la vida del campamento y de las pequeñas plantaciones. En el clan casi todos eran parientes: el patriarca tenía autoridad absoluta, dirigía las migraciones, repartía la ocupación de los pastos, y era juez en los conflictos que surgían.

En las historias de los patriarcas se destacan las mujeres fuertes como Sara, Agar, Rebeca y Lía. Ellas no tenían poder político, pero ejercían influencia sobre aquellos. Mientras los cananeos sacrificaban a sus hijos a los dioses, para los seminómadas, el niño era la esperanza de la sobrevivencia, la esperanza de la formación del pueblo. Los nacimientos, la vida, la muerte, las relaciones marido-esposa, mujer-hijo y entre hermanos eran las relaciones de este grupo.

Teológicamente, los patriarcas no conocían a Yahveh; rendían culto a un Dios paterno, a un Dios personal. En el seminomadismo, no había vida posible sin la cohesión y la inserción grupal. El Dios paterno era, pues, un Dios familiar, del grupo, un Dios nómada en el sentido de que se sucedía en la experiencia colectiva del clan. Este celebraba la Pascua -rito de pastores en la estepa- y la circuncisión.

Cuando se dice el Dios de tus padres, el Dios de Abraham, el Dios de Isaac, el Dios de Jacob, posiblemente son cuatro experiencias de Dios, o tres experiencias teológicas:

- $\quad$ Dios de Isaac: temor de Isaac.

- Dios de Jacob: fuerte de Jacob.

- Dios de Abraham: todopoderoso.

Lo importante de esta teología es su vinculación a personas. Es un Dios que protege y bendice a las personas para que los sedientos encuentren agua (Gn 16,7; $21,8 s s$.), los hambrientos encuentren pan (Gn 26,37), el rebaño se reproduzca (Gn 29). Es un Dios conocido por varios nombres: 'El 'Elyôn Altísimo (Gn 14,19-24); 
'El Rồ, el que aparece, el que ve (Gn 16,13); 'El Šadday, Dios de la montaña, de la estepa (Gn 17,1); 'El 'Olam, Dios eterno (Gn 21,33); 'El Bet-'El, Dios de Bet-El (Gn 31,13).

Es el Dios de la promesa (Gn 15,5-7; 26,1-6): un hijo a Abraham, una tierra, una descendencia numerosa, un pueblo. Es él quien protege en el camino (Gn 28,15; 46,3-4) y permanece junto a los suyos. El culto no tiene determinado lugar sagrado: es un rito familiar, está donde está el grupo, no tiene sacerdotes ni templo. Está ligado a la Pascua (= paso = cambio de pastos), y es una fiesta popular, cuyo origen está en los ritos de los pastores en el momento de partir hacia sus migraciones. Construyen un altar provisorio: es un alto en el camino (Gn 12,7-8; 13,3-4; 22,9; 33,20; etc.), un lugar sagrado para el momento. En ese lugar sagrado listo para el sacrificio -donde seguramente los sacrificios de niños eran prácticas comunes- es donde el Dios de los israelitas se separa de cualquier tipo de sacrificio humano y fundamenta su ética en el no matar.

\section{Conclusiones}

¡No alargues la mano contra los nińos! Esta oración, con la que titulamos este artículo, nos sirvió de hilo conductor del mismo, al aproximarnos a algunas prácticas de sacrificio de niños en el Antiguo Medio Oriente, no para decir que esto siempre ha existido, sino para tomar distancia de cualquier forma de aniquilación de la vida humana, en especial relacionada con los niños y niñas, que son los eslabones más frágiles de la sociedad.

En las sociedades adultocéntricas las voces de los niños son silenciadas, pero no queremos solo cuestionar, sino también contribuir en el proceso de liberación de estas vidas al tiempo que buscamos una resignificación de su tejido social a partir de su realidad contextual y de la ubicación de estos cuerpos en la historia bíblica.

En este recorrido pudimos confirmar que el sacrificio de primogénitos a Yahveh pudo haber sido una práctica en Israel, pero esta obligación pudo ser substituida por otro tipo de ofrenda. Algunos autores - como de Vaux ${ }^{51}$ - rechazan la idea de algún tipo de sacrificio humano dedicado a Yahveh. La literatura deuteronomista es constantemente critica a dicha práctica y niega que Yahveh alguna vez haya estado vinculado a este tipo de ofrendas sacrificiales. No obstante, vale la pena preguntarnos hoy si es posible, tan solo mediante el imperativo ético de no matar, acabar con los abusos y asesinatos de niños y nińas.

\footnotetext{
${ }^{51}$ De Vaux, Instituciones del Antiguo Testamento.
} 
Este estudio nos ha permitido descubrir que existe un relato que ha sido reconocido como central y sobre el cual se ha fundado la fe de Israel (Gn 22,1-19), mientras se han ignorado microrrelatos sobre los cuales reposan tradiciones femeninas que son invisibilizadas, como es el caso de la narrativa de Gn 21,1-21.

Las tradiciones femeninas son una riqueza para los relatos y han servido como pretextos para los macrorrelatos. Ellas nos rememoran a un tiempo en el que la divinidad se revelaba directamente a las mujeres sin la intermediación de un varón santo con dotes sacerdotales. Junto a esto, el protagonismo de los niños en la historia también ha sido invisibilizado: ellos han sido simples bueyes expiatorios que son conducidos como ovejas al matadero, sin voz, sin voto, sin derecho, despojados de su dignidad e incluso de su vida.

Los relatos en cuestión, al ser puestos paralelamente, dejan ver unas similitudes y contrastes importantes en cuanto a su dependencia literaria. Por otro lado, se percibieron también las relaciones intrafamiliares, y de las de estas con la divinidad, en las que las intrigas, el engaño y la mentira son experiencias humanas que se viven al interior de un clan familiar.

Las personas y la divinidad son diversas y distintas. Por un lado, Abraham, quien habla con Dios, es probado y luego detenido por el mismo Dios en razón de su obediencia. Isaac, en cambio, no tiene ningún contacto con Dios y al parecer tampoco con sus congéneres; se relaciona solo con su hermano, pero esto viene a ser también un problema que genera el rechazo del primer hijo de Abraham, o al menos sirve de excusa para que sea entregado a la muerte.

Así pues, las tramas familiares que se evidencian en estos relatos son reveladoras y muy importantes para la teología, y tienen mucho qué decir hoy a una sociedad que continúa sacrificando niños y niñas.

Por consiguiente, cuestionamos la forma como los infantes son tratados hoy en el seno de nuestras familias, de la Iglesia y de la sociedad adultocéntrica de la que ellos hacen parte, pero en la que parecen ser invisibles. El tránsito entre los sacrificios del ayer y del hoy se justifica en el hecho de que, los sacrificios de infantes en el mundo antiguo -pertenecieran a la esfera religiosa o no- revelan un sistema macabro de una sociedad que aniquila a los más débiles.

Por eso no es absurdo afirmar que continuamos asistiendo a la inmolación de infantes, como lo demuestra el reciente caso de Génesis Rua, nińa secuestrada, torturada, violada, asesinada y quemada en Fundación (departamento de Magdalena, Colombia). Estos cuerpos son las víctimas expiatorias de un sistema patriarcal falocéntrico, que continúa imperando en nuestra sociedad. 
Nuestros niños siguen siendo amordazados, silenciados, maltratados, humillados, violados y asesinados ante el silencio cómplice del Estado y de nuestras instituciones eclesiales, y muchas veces incluso ante el encubrimiento de los adultos.

¿Acaso será posible que algún Dios, algún humano o alguna institución haga algo por detener el sacrificio de los niños y niñas en nuestra sociedad? Es imposible hablar de paz, perdón y reconciliación sin pasar por la casa, sin observar lo que está sucediendo en ella. El rechazo contundente a los abusos, a los asesinatos de nińos y niñas, debería ser más que un simple imperativo ético: debería ser una actitud inherente a la condición humana, para alcanzar la paz estable y duradera que tanto añora nuestro país.

No podemos seguir siendo cómplices de esta crueldad. Por eso consideramos de vital importancia gritar al unísono: ¡No alargues tu mano contra los niños y las niñas! ¡Levántalos y dales la mano!

\section{Referencias}

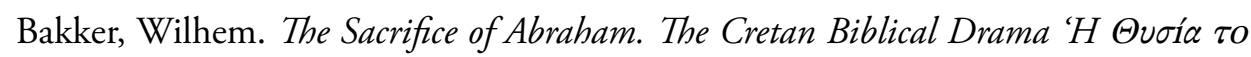
Aßpáa and Western European and Greek Tradition. Birmingham (U. K.): University of Birmingham, 1978.

Barrios, Hernando. "Del sacrificio de 'Abrahan' al sacrificio de su 'descendencia': exégesis y teología narrativa del sacrificio en Génesis 22,1-19”. Franciscanum LII/ 153 (2010): 15-55.

Bergen, Robert. "The Role of Genesis 22, 1-19 in the Abraham Cycle: A ComputerAssisted Textual Interpretation". Criswell Theological Review 4/2 (1990): 313-326.

Brueggemann, Walter. Teología del Antiguo Testamento un juicio a Yahvé. Testimonio. Contención. Defensa. Salamanca: Sígueme, 2007.

Camelo, Miguel. “Padre... y ¿đónde está el cordero para el holocausto?” Una aproximación literaria a la Aquedá en Génesis 22,1-19”. Franciscanum LII/153 (2010): 99-126.

Coats, George W. “Abraham's Sacrifice of Faith: A Form-Critical Study of Genesis 22”. Interpretation 27/4 (1973): 389-400. https://doi. org/10.1177/002096437302700402.

Day, Jhon. Molech: A God of Human Sacrifice in the Old Testament. Cambridge (U. K.): Cambridge University Press, 1989.

De Vaux, Roland. Instituciones del Antiguo Testamento. Barcelona: Herder, 1976. 
Derrida, Jacques. Dar la muerte. Barcelona: Paidós, 2000.

Desroches Noblecourt, Christiane. La mujer en tiempos de los faraones. Madrid: Editora Complutense, 2009.

Dewrell, Heath D. Child Sacrifice in Ancient Israel. University Park (PA): Eisenbrauns, 2017.

Eissfeldt, Otto. Molk als Opferbegriff im Punischen und Hebräische und das Ende des Gottes Moloch. Halle: Niemeyer, 1935.

Gaiser, Frederick J. "Sarah, Hagar, Abraham-Hannah, Peninnah, Elkanah: Case Studies in Conflict". Word \& World 34/3 (2014): 273-284.

Gaitán, Tarcicio. "Métodos de interpretación de la Biblia". Cuestiones teológicas 33/79 (2006): 141-169.

Gottwald, Norman K. La Biblia hebrea. Una introducción socio-literaria. Bogotá: Seminario Teológico Presbiteriano, 1992.

Gregory, Bradley. "Abraham as the Jewish Ideal: Exegetical Traditions in Sirach 44: 19-21". Catholic Biblical Quarterly, 70/1 (2008): 66-81.

Hernández, Ana. "El sacrificio de Isaac". Revista digital de iconografia VI/11 (2014): 65-78.

Kessler, Edward. Bound by the Bible. Jews, Christians and the Sacrifice of Isaac. Cambridge (U. K.): Cambridge University Press, 2004.

Kierkegaard, Sören. Temor y temblor. Madrid: Editora Nacional, 1981.

Mena-López, Maricel. "Because of an Ethiopian Woman. Reflections on Race, Gender, and Religion". En Biblical Feminist Intercultural Theology: Latina Explorations for a Just World, editado por María Pilar Aquino y María José Rosado-Nunes, 145-165. Maryknoll (NY): Orbis Books 2007.

. Panorama biblico latinoamericano. Aproximaciones desde lo femenino y la negritud. Bogotá: Fundación Universitaria San Alfonso, 2010.

Momanyi, Oscar. "The Children of Sarah, Hagar and Mary. A Feminist Perspective on Judaism, Islam and Chistianity”. The Way 52/2 (2017): 73-87.

Montoya G. Brígida. "Comportamiento de la violencia intrafamiliar, Colombia, 2016”. En Forensis 2016. Datos para la vida, editado por el Instituto Nacional de Medicina Legal y Ciencias Forenses, 210-315. Bogotá: Instituto Nacional de Medicina Legal y Ciencias Forenses 2016. 
Navarro Puerto, Mercedes. Religión, sexualidad y violencia: lectura bíblica feminista de textos del Génesis. Madrid: Trotta, 2008.

Navarro Puerto, Mercedes, e Irmtraud Fischer (eds.). La Torah, Estella (Navarra): Editorial Verbo Divino, 2009, 263-304.

Neoh, Joshua. "Law and Love in Abraham's Binding of Isaac". Law and Humanities 9/2 (2015): 237-261.

Peterson, Carl. "Military Service as Child Sacrifice: Oedipal and Odyssean Perspectives", International Journal of Applied Psychoanalytic Studies 12/1 (2015): 36-52.

Pikaza, Xavier. Mujeres de la Biblia judía. Barcelona: Clie, 2013.

Römer, Thomas. "Abraham's Righteusness and Sacrifice: How to Understand (and Traslate) Genesis 15 and 22". Lousanne: Communio Viatorum 54 (2012): 3-15.

Schwantes, Milton. Historia de los orígenes de Israel. Quito: Centro Bíblico Verbo Divino, 2003. Sufrimiento y esperanza en el exilio. Historia y teología del pueblo de Dios en el siglo VI a. C. Santiago: Ediciones Rehue Ltda., 1991

Towner, Wayne S. Genesis. Louisville (KY): Westminster John Knox Press, 2001.

Von Rad, Gerhard. Genesis. Philadelphia (PA): Westminster John Knox Press, 1972.

Weippert, Helga. "Das deuteronomistische Geschichtswerk. Sein Ziel und Ende in der neueren Forschung". ThR 50 (1985): 213-249.

Westermann, Claus. Genesis 12-36. Minneapolis (MN): Fortress Press, 1985.

Wood, W. H. "Jar-Burial Customs and the Question of Infant Sacrifice". The Biblical World 36/4 (1910): 227-234.

Zucker, David J. "What Sarah Saw: Envisioning Genesis 21:9-10". The Jewish Bible Quarterly 36/1 (2008): 54-62. 